Nigerian Journal of Physiological Sciences 24 (2): 141 -147 @Physiological Society of Nigeria, 2009

Available online/abstracted at http://www.bioline.org.br/np; www.ajol.info/journals.njps; www.cas.org

\title{
ROLE OF ADRENERGIC RECEPTORS IN THE CAFFEINE-INDUCED INCREASE IN GLUCOSE UPTAKE BY THE CANINE HINDLIMB
}

\author{
H. M. SALAHDEEN AND A. R. A. ALADA*
}

\begin{abstract}
*Department of Physiology, College of Medicine, University of Ibadan, Ibadan, Oyo State, Nigeria. E-mail: dralada@yahoo.com
\end{abstract}

\begin{abstract}
Summary: The present study was designed to investigate the effects of alpha and beta adrenergic receptor blockers on caffeine-induced increase in canine hindlimb glucose uptake. The study was carried out on fasted male anaesthetized dogs divided into five groups (5dogs per group). Each dog was given a bolus injection of normal saline, caffeine $(6 \mathrm{mg} / \mathrm{kg})$ caffeine after pretreatment with prazosin $(0.2 \mathrm{mg} / \mathrm{kg})$. Caffeine $(6 \mathrm{mg} / \mathrm{kg})$, caffeine after pretreatment with prazosin $(0.2 \mathrm{mg} / \mathrm{kg})$, propranolol $(0.5 \mathrm{mg} / \mathrm{kg})$ or combination of prazosin $(0.2 \mathrm{mg} / \mathrm{kg})$ and propranolol $(0.5 \mathrm{mg} / \mathrm{kg})$. The experiments were carried out under resting and exercising conditions of the hindlimb. Hindlimb glucose uptake (HGU) was calculated as the product of blood flow and arterio-venous glucose difference. Blood glucose was determined by the glucose oxidase method and blood flow to the hindlimb was determined by time-collection method. The results showed that pretreatment of the animal with either prazosin or propranolol significantly reduced caffeine-induced hyperglycemia, glucose extraction and hindlimb glucose uptake at rest. The two blockers also separately reduced caffeine-induced hyperglycemia during contraction of the hindlimb. Prazosin or propranolol did not however influence the effect of caffeine on glucose extraction and hindlimb glucose uptake during contraction of the hindlimb. It was therefore concluded that alpha and beta adrenergic receptors are involved in caffeine induced responses at rest and not during hindlimb contraction.
\end{abstract}

Key words: Adrenergic receptors, Caffeine, dog, Glucose uptake,

\section{Introduction}

Caffeine is a methylxantine commonly found in many food substances including coffee, chocolate, and tea (Graham et al, 2001; Petrie et al, 2004; Robinson et al, 2004). It is also found in kolanut which is a common masticatory in Nigeria (Ogutuga, 1975; Chukwu et al, 2006). Caffeine is known to affect many tissues in the body including central nervous system (Costill et al, 1978; Fredholm et al, 1999), respiratory system and carbohydrate metabolism (Greer et al, 2000; Graham, 2001).

Reports on the effect of caffeine on glucose disposal in the body have been inconsistent depending in many cases on the animal species. For instance, while caffeine produced decreases in glucose uptake in human skeletal muscle (Graham and Spriet 1995; Greer et al, 2001; Han et al, 1998; Keijzers et al, 2002), isolated adipose tissue (Steinfelder and Petho-Schramm, 1990) and rat contracting hindlimb (Vergauwen et al, 1994), it caused significant increases in glucose uptake in canine hepatic tissues (Pencek et al, (2004). Recently, we also showed that acute administration of caffeine to the hindlimb increased its glucose uptake by $272 \%$ and $411 \%$ at rest and during contraction respectively (Salahdeen and Alada, 2009). When kolanut extract was administered to canine hindlimb under similar experimental conditions, the increase in glucose uptake by the contracting hindlimb was about $634 \%$. Since the pattern of increase in glucose uptake in response to kolanut extract was essentially similar to that of pure caffeine, it was therefore suggested that the increases in glucose uptake caused by kolanut was due to the presence of caffeine in the extract.

The mechanisms by which caffeine/kolanut caused significant increases in glucose uptake by the canine hindlimb are not known. However, some workers (Han et al, 1998; Graham et al, 2000; 2001; Thong et al, 2002) have reported a slight but significant increase in plasma adrenaline levels following ingestion of caffeine in man. It is unknown whether the effect of caffeine on the glucose uptake in the hindlimb of dog is mediated entirely or in part by the reported increased plasma adrenaline level. Apart from adrenaline release, other mechanisms that have been suggested include: antagonism of adenosine receptors (Fredholm, 1998), influx of Ca++ (Jensen et al, 2007; Wright et al, 2005) and inhibition of phosphodiestrase to increase cAMP (Fredholm et $a l, 1999)$. Since adrenaline acts through both alpha and beta adrenergic receptors (Oyebola and Alada, 1997). The aim of the present study was to find the contribution of adrenergic receptors in the mechanism by which caffeine increased hindlimb glucose uptake; the present study was therefore designed to investigate the effects of alpha and beta adrenergic blockers on the caffeine-induced increase in the hindlimb glucose uptake of dogs. 


\section{Materials and methods}

Male mongrel dogs weighing $11-13 \mathrm{~kg}$ were used for the study. Each animal was fasted for 18$24 \mathrm{hr}$ before the start of an experiment. Anaesthesia was induced by intravenous (i.v.) injection of sodium pentobarbitone, $30 \mathrm{mg} / \mathrm{kg}$. Light anesthesia was maintained with supplemental doses of i.v. sodium pentobarbitone as necessary. The trachea was intubated using endotracheal tube and the animal was allowed to breathe room air $\left(25{ }^{0} \mathrm{C}\right)$ spontaneously.

The right and left femoral veins and arteries were cannulated. The cannula in the right femoral vein was moved into an extracorporeal position and a non-crushing clamp was applied to its free end. The left femoral vein was cannulated for the administration of drug and left femoral artery was also cannulated and connected to a two-Channel physiographic recorder through pressure transducer model 7070 Gemini (Ugo Basil) to monitor blood pressure and heart rate.

The right femoral nerve was isolated and muscular contraction was induced by electrical square pulses of $0.2 \mathrm{~ms}$ duration using electrical student stimulator to the nerve (Brooks Instruments, UK). The output voltage was limited to $10 \mathrm{~Hz}$ for nonpainful muscle contraction for thirty minutes (Hamada et al, 2003). At the end of surgical procedure, sodium heparin $300 \mathrm{unit}$ per $\mathrm{kg}$ body weight was administered intravenously to prevent blood clotting. After all surgical procedures were completed, a 60-90 minutes stabilization period was observed. The blood flow to the hindlimb was measured by time collection of the blood from the right femoral vein as previously described by Oyebola and Durosaiye (1988). Arterial and venous blood samples for glucose estimation were obtained from the cannula placed in the right femoral artery and vein respectively. After stabilization, basal measurements of the femoral venous blood flow, arterial and venous glucose were determined. The study was carried out on the right hindlimb of the dogs under two conditions viz: resting (basal) and during hindlimb muscle contractions conditions. The experiments were carried out on five groups of dogs:

\section{Group I (Control)}

Five dogs were studied. The blood samples for basal glucose measurements were obtained from both right arterial and venous cannulae. A bolus injection of normal saline $(0.1 \mathrm{ml} / \mathrm{kg})$ was then given through the femoral vein. Blood pressure and blood flow measurements were recorded, while the arterial and venous blood samples for glucose estimation were obtained at $5 \mathrm{~min}, 10 \mathrm{~min}, 15 \mathrm{~min}$, 20min, 25min, 30min, 45min, 60min, 75min, and 90min post-injection. The procedures for blood flow monitoring, arterial and venous blood sampling were carried out during the hindlimb contraction and after stimulation of the nerve.

Group II: Five dogs were studied. Following collections of arterial and venous blood samples for basal blood glucose levels and basal recording of blood pressure and blood flow, a bolus injection of caffeine at a dose of $6 \mathrm{mg} / \mathrm{kg}$, was given i.v. through the femoral vein followed by stimulation of femoral nerve to produce hindlimb contraction for thirty minutes. The procedures for blood pressure, and blood flow monitoring, arterial and venous blood sampling were carried out as in group I at rest during the hindlimb contraction and after hindlimb contraction.

Group III: Five dogs were studied. The animals were pre-treated with prazosin $(0.2 \mathrm{mg} / \mathrm{kg})$ and thirty minutes were allowed for the drug to take effect followed by i.v. injection of caffeine $(6 \mathrm{mg} / \mathrm{kg})$. The procedures for blood pressure and blood flow monitoring, arterial and venous blood sampling were carried out as in group I at rest, during hindlimb contraction and after contraction.

Group IV: Five animals were pre-treated with propranolol $(0.5 \mathrm{mg} / \mathrm{kg})$, and thirty minutes were allowed for the drug to take effect followed by i.v. injection of caffeine $(6 \mathrm{mg} / \mathrm{kg})$. The procedures for blood pressure and blood flow monitoring, arterial and venous blood sampling were carried out as in group I at rest, during hindlimb contraction and after contraction.

Group V: Five dogs were pre-treated with both prazosin $\quad(0.2 \mathrm{mg} / \mathrm{kg})$ and propranolol $(0.5 \mathrm{mg} / \mathrm{kg})$.After thirty minutes i.v. injection of caffeine $(6 \mathrm{mg} / \mathrm{kg})$ was given. The procedures for blood pressure and blood flow monitoring, arterial and venous blood sampling were carried out as in group I at rest, during hindlimb contraction and after contraction.

\section{Blood glucose measurement}

Blood glucose was determined with one touch basic-plus glucometer. The meter was checked against the standard glucose solution at regular interval to ensure accuracy. Result of blood glucose measurement using glucometer correlates excellently with the results obtained from standard laboratory methods (Ajala et al., 2003; Devreese and Leroux-Roels, 1993). Glucose uptake was calculated as the product of the $(\mathrm{A}-\mathrm{V})$ glucose and blood flow.

Data were analyzed using Microsoft Excel statistical package. All values given are the mean \pm S.E of the variables measured. Significance was assessed by the analysis of variance (ANOVA) followed by a post hoc Fisher's PLSD test for 
Adrenergic receptors and caffeine on canine hindlimb glucose uptake

multiple comparisons. $\mathrm{P}$ values of 0.05 or less were taken as statistically significant.

\section{Results}

The effects of caffeine on arterial blood glucose levels, arterio-venous difference (A-V) glucose, hindlimb blood flow and glucose uptake (HGU) are shown in table 1 and 2 and figures land 2.

\section{Effects of caffeine on arterial blood glucose}

Effects of caffeine on arterial blood glucose levels at rest and during hindlimb muscular contraction before and after adrenergic receptors blockade are shown in table 1. At rest, caffeine significantly increased arterial blood glucose levels. This increase in arterial blood glucose was immediate and remained sustained throughout the post-injection observation period. However, the increase in blood glucose levels was significantly reduced by prazosin and completely abolished by either propranolol or a combination of prazosin with propranolol.

Following hindlimb contraction, caffeine also caused significant increase in arterial blood glucose levels. There was however no significant difference in the increases in blood glucose levels produced by caffeine at rest and following hindlimb contraction. Pretreatment of the animal with either prazosin or propranolol significantly reduced the caffeine-induced increases in blood glucose levels during hindlimb contraction. Pretreatment of the animal with a combination of prazosin and propranolol also completely abolished the caffeineinduced increases in arterial blood glucose levels during hindlimb contraction.

Effect of caffeine on hindlimb blood flow

Effect of caffeine on hindlimb blood flow at rest and during hindlimb contraction before and after adrenergic receptor blockade is shown on figure 1. Figure 1a shows that caffeine produced significant decreases in blood flow to the hindlimb at rest. Pretreatment of the animal with either prazosin, or propranolol did not produce any significant difference in the effect of caffeine on hindlimb blood flow at rest. However a combination of the two blockers significantly reduced the effect of caffeine on the blood flow.

In Fig $1 \mathrm{~b}$ however, hindlimb contraction significantly abolished the effect of caffeine on hindlimb blood flow. That is there were there significant increases in blood flow to the hindlimb even in the presence of prazosin or propranolol. In other words, the effect of caffeine on hindlimb blood flow was reversed during hindlimb contraction.

\section{Effects of caffeine on (A-V) glucose}

The effect of caffeine on hindlimb glucose extractions is shown in table 2. Caffeine significantly increased glucose extraction by the hindlimb at rest from basal value of $4.3 \pm 0.2 \mathrm{mg} / \mathrm{dl}$ to a maximum value of $29 \pm 1.5 \mathrm{mg} / \mathrm{dl}$. Pretreatment of the animal with alpha-blocker, prazosin significantly reduced the maximum level of $(\mathrm{A}-\mathrm{V})$ glucose to $22 \pm 0.5 \mathrm{mg} / \mathrm{dl}$. Pretreatment of the animal with propranolol however, abolished the significant increase in (A-V) glucose caused by caffeine at rest.

When the hindlimb was contracted, caffeine increased the $(\mathrm{A}-\mathrm{V})$ glucose of the hindlimb from a basal value $4.3 \pm 0.3 \mathrm{mg} / \mathrm{dl}$ to a maximum value of $35 \pm 1.4 \mathrm{mg} / \mathrm{dl}$. Pretreatment of the animal with either prazosin, propranolol or both prazosin and propranolol during the hindlimb contracting state caused significant reduction in hindlimb glucose extraction (not abolished) in response to caffeine.
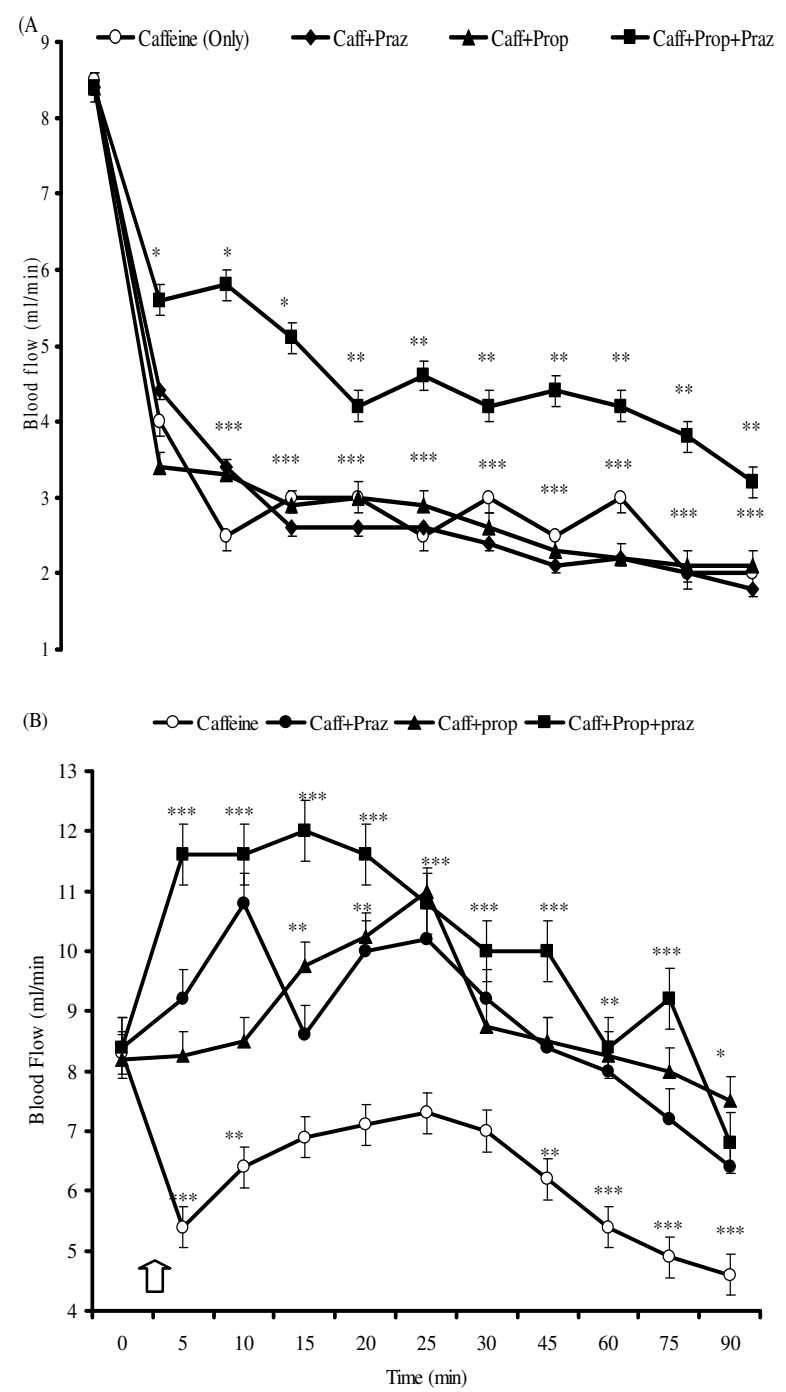

Fig. 1: Effects of intravenous injection of caffeine $(6 \mathrm{mg} / \mathrm{kg})$ on (A) blood flow ( $\mathrm{ml} / \mathrm{min})$ before and after blockage of Alpha, beta and Alpha and beta receptors at rest and (B) during hindlimb contraction in dogs. $(N=5)(* p<0.05$; **p<0.01; $* * * p<0.001)$. Arrow shows point of drug injection. 

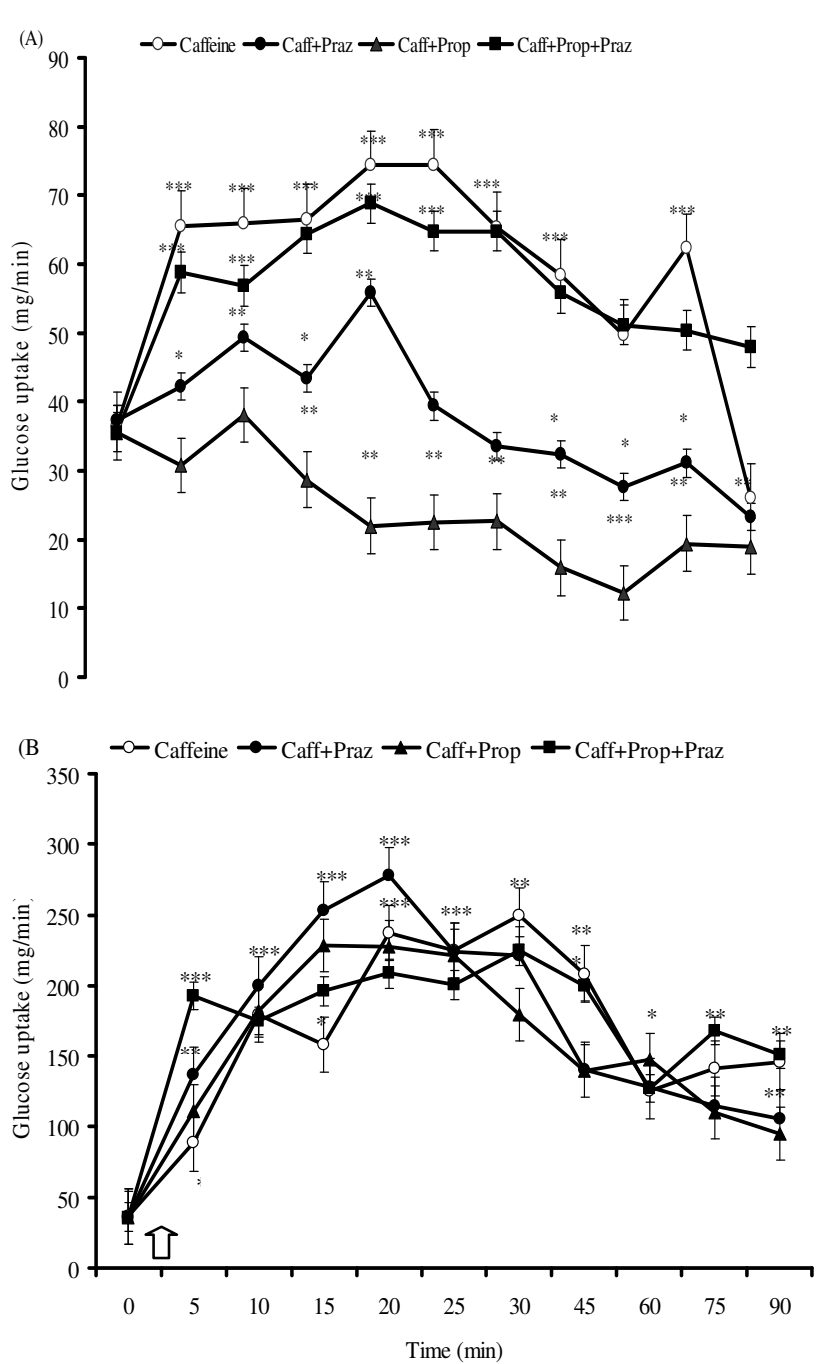

Figure 2: Effects of intravenous injection of caffeine $(6 \mathrm{mg} / \mathrm{kg})$ on (A) glucose uptake $(\mathrm{mg} / \mathrm{min})$ before and after blockage of Alpha, beta and Alpha and beta receptors at rest and $(B)$ during hindlimb contraction in dogs. $(N=5)(* p<0.05 ; * * p<0.01$; $* * * p<0.001)$. Arrow shows point of drug injection.

\section{Effect of caffeine on hindlimb glucose uptake}

Figure 2a shows the effect of caffeine on the hindlimb glucose uptake in a resting hindlimb. Caffeine caused a significant increase in the hindlimb glucose uptake at rest. The hindlimb glucose uptake increased from $35.5 \pm 4.2 \mathrm{mg} / \mathrm{min}$ to $130.6 \pm 2.6 \mathrm{mg} / \mathrm{min}(268 \%)$. The increase in hindlimb glucose uptake caused by caffeine was significantly reduced by propranolol, while prazosin abolished it.

Following hindlimb contraction, the glucose uptake increased significantly from 35.5 \pm 4.2 $\mathrm{mg} / \mathrm{min}$ to $160.2 \pm 2.3 \mathrm{mg} / \mathrm{min}(350 \%)$. The increase in hindlimb glucose uptake caused by caffeine during contraction is however neither affected by prazosin nor propranolol (fig $2 \mathrm{~b}$ ).

\section{Discussion}

The observed increases in blood glucose levels, hindlimb glucose extraction, and hindlimb glucose uptake at rest and during contraction following caffeine-induced hyperglycemia are consistent with our earlier findings in similar dog experiments (Salahdeen and Alada, 2009), where it was suggested that the increases in hindlimb glucose uptake and extraction are due to increases in arterial blood glucose levels. It was also proposed that the effect of caffeine on blood glucose levels could be a result of its stimulation of adrenal medulla to release adrenaline into the blood stream. Several studies (Graham et al., 2000; Greer et al., 2001; Keijzers et al., 2002; Thong et al., 2002; Pencek et al., 2004; Lee et al., 2005) have shown that administration of caffeine caused significant increases in the plasma adrenaline levels. Adrenaline is a well- known hyperglycemic agent (Deibert and DeFronzo 1979; Fain and GarciaSainz 1983; Alada and Oyebola, 1994). The mechanism by which adrenaline increases blood glucose levels is well established. It involves both glycogenolytic and gluconeogenetic pathways in the liver and skeletal muscle (Akiba et al 2004).

The significant reduction in the large hyperglycemic response to caffeine injection by prazosin or propranolol was of great interest. Previous workers have shown in man (Antonis et al, 1967) cat (Aljibouri et al, 1980) rat (Oyebola and Alada 1993) and dog (Alada and Oyebola 1996) that adrenaline-induced hyperglycemia was abolished by a combination of alpha- and betaadrenergic blocking agents. The later observations are consistent with the result of the present study whereby a combination of prazosin and propranolol abolished the effects of caffeine on blood glucose. The decrease in hindlimb glucose extraction and hindlimb glucose uptake produced by caffeine following pretreatment of the dog at rest with either prazosin or propranolol suggests the involvement of both alpha and beta adrenergic receptors in the effect of caffeine on hindlimb glucose uptake at rest. Failures of the two blockers to alter these variables during hindlimb contraction shows the non-involvement of both alpha and beta adrenoceptors in response to caffeine during hindlimb contraction. It is however instructive to note that the significant reduction in blood flow to the hindlimb in response to caffeine administration at rest was completely abolished during hindlimb contraction. In other words, caffeine had no significant effect on the blood flow to the hindlimb during contraction. Again, failure of the adrenergic receptor blockers to alter the effect of caffeine on the hindlimb blood flow during contraction shows that the adrenergic receptors are not involved in the effect of caffeine on blood flow during contraction of the hindlimb. 
Table1: Effects of caffeine $(6 \mathrm{mg} / \mathrm{kg})$ on arterial blood glucose levels $(\mathrm{mg} / \mathrm{dl})$ before and after blockade of Alpha, Beta and Alpha and Beta receptors at rest and during contraction of hindlimb of dogs. Values are expressed as Mean \pm SEM. *(p<0.05);** $(p<0.01) ; * * *(p<0.001) n=5$ in each group.

\begin{tabular}{|c|c|c|c|c|c|c|c|c|c|c|c|c|}
\hline Treatment & & $0(\min )$ & $5(\min )$ & $10(\min )$ & $15(\min )$ & $20(\min )$ & $25(\min )$ & $30(\min )$ & $45(\min )$ & $60(\min )$ & $75(\min )$ & $90(\min )$ \\
\hline \multirow[t]{2}{*}{ Normal Saline } & Rest & $99.3 \pm 1.4$ & $99.4 \pm 0.9$ & $99.6 \pm 0.8$ & $98.2 \pm 1.9$ & $99.6 \pm 1.2$ & $98.4 \pm 1.0$ & $98.2 \pm 1.4$ & $99.6 \pm 0.9$ & $97.8 \pm 0.8$ & $97.6 \pm 1.0$ & $98.2 \pm 0.4$ \\
\hline & Contraction & $99.2 \pm 1.4$ & $109 \pm 5.4$ & $115 \pm 5.7$ & $118 \pm 6.5$ & $120 \pm 6.6$ & $115.8 \pm 6.1$ & $117 \pm 7.1$ & $114 \pm 5.6$ & $115 \pm 4.2$ & $116 \pm 5.5$ & $115 \pm 5.8$ \\
\hline \multirow[t]{2}{*}{ Caffeine (only) } & Rest & $99.2 \pm 1.4$ & $137 \pm 1.9 * *$ & $140 \pm 1.2 * *$ & $140 \pm 1.9 * *$ & $138 \pm 1.6^{* *}$ & $139.4 \pm 1.4 * * *$ & $134 \pm 1.5 * *$ & $132 \pm 2.8 * *$ & $124 \pm 1.2 * *$ & $126 \pm 1.5^{* *}$ & $117 \pm 1.3 * *$ \\
\hline & Contraction & $99.3 \pm 1.2$ & $131 \pm 3.7$ & $154 \pm 3.8 *$ & $160 \pm 3.7 * *$ & $156 \pm 5.1 * *$ & $151.2 \pm 3.6^{* *}$ & $156 \pm 4.1 *$ & $148 \pm 3.4 *$ & $149 \pm 2.1 *$ & $149 \pm 2.1 *$ & $148 \pm 4.2 *$ \\
\hline \multirow[t]{2}{*}{ Caffeine+Prazosin } & Rest & $99 \pm 1.5$ & $102 \pm 5.3$ & $106 \pm 8.8$ & $111 \pm 8.0$ & $110 \pm 9.2$ & $103 \pm 5.8$ & $102 \pm 5.5$ & $102 \pm 5.4$ & $108 \pm 4.4$ & $105 \pm 2.8$ & $96.2 \pm 4.4$ \\
\hline & Contraction & $99.2 \pm 2.0$ & $113 \pm 5.0$ & $119 \pm 1.7$ & $124 \pm 6.4 *$ & $124 \pm 4.0 * *$ & $119 \pm 3.8 * *$ & $121 \pm 4.2 * *$ & $110 \pm 3.6$ & $111 \pm 4.4$ & $108 \pm 3.5$ & $110 \pm 3.6$ \\
\hline \multirow[t]{2}{*}{ Caffeine+Prpranolol } & Rest & $99.4 \pm 1.8$ & $85.4 \pm 2.4 * *$ & $76.2 \pm 2.7 * *$ & $72.2 \pm 2.9 * *$ & $74.8 \pm 3.7 * *$ & $71.8 \pm 3.2 * *$ & $69.8 \pm 3.8 * *$ & $74.8 \pm 3.8 * *$ & $71.8 \pm 4.5 * *$ & $75.8 \pm 5.2 * *$ & $75.4 \pm 5.1 * *$ \\
\hline & Contraction & $99.2 \pm 0.8$ & $111 \pm 4.2$ & $123 \pm 4.3 * *$ & $128 \pm 5.0^{* *}$ & $125 \pm 0.6$ & $123.2 \pm 1.3$ & $111.2 \pm 3.5$ & $104.2 \pm 2.9$ & $103.2 \pm 1.8$ & $96.4 \pm 3.6$ & $94.8 \pm 3.2 * *$ \\
\hline $\begin{array}{c}\text { Caffeine } \\
+ \text { Prazosin+ } \\
\text { Propranolol }\end{array}$ & $\begin{array}{c}\text { Rest } \\
\text { Contraction }\end{array}$ & $\begin{array}{l}103 \pm 2.0 \\
99.3 \pm 2.0\end{array}$ & $\begin{array}{l}95.4 \pm 3.4 \\
106 \pm 4.3\end{array}$ & $\begin{array}{l}101 \pm 3.4 \\
102 \pm 2.9\end{array}$ & $\begin{array}{l}103 \pm 4.0 \\
103 \pm 3.8\end{array}$ & $\begin{array}{l}103 \pm 4.3 \\
98.8 \pm 4.3\end{array}$ & $\begin{array}{l}105.4 \pm 3.4 \\
99.4 \pm 2.4\end{array}$ & $\begin{array}{l}103 \pm 3.7 \\
105 \pm 3.3\end{array}$ & $\begin{array}{l}103 \pm 2.9 \\
101 \pm 2.7\end{array}$ & $\begin{array}{l}99 \pm 1.9 \\
95.2 \pm 1.2 *\end{array}$ & $\begin{array}{l}95.8 \pm 2.8 \\
93.2 \pm 1.2 * *\end{array}$ & $\begin{array}{l}90.6 \pm 2.8^{*} \\
89.8 \pm 1.0^{* * *}\end{array}$ \\
\hline
\end{tabular}

Table 2: Effects of caffeine (6mg/kg) on arterial-venous blood glucose differences (A-V) levels ( $\mathrm{mg} / \mathrm{dl})$ before and after blockade of Alpha, Beta and Alpha and Beta receptors at rest and during contraction of hinmdlimb of dogs. Values are expressed as Mean \pm SEM. $*(p<0.05) ; * *(p<0.01) ; * * *(p<0.001) n=5$ in each group

\begin{tabular}{|c|c|c|c|c|c|c|c|c|c|c|c|}
\hline Treatment & $0(\min )$ & $5(\min )$ & $10(\min )$ & $15(\min )$ & $20(\min )$ & $25(\min )$ & $30(\min )$ & $45(\min )$ & $60(\min )$ & $75(\min )$ & $90(\min )$ \\
\hline \multirow{2}{*}{ Normal Saline } & $4.2 \pm 0.2$ & $4.2 \pm 0.2$ & $5.2 \pm 0.5$ & $4.2 \pm 0.6$ & $4.4 \pm 0.2$ & $5.0 \pm 0.3$ & $5.6 \pm 0.2$ & $4.2 \pm 0.2$ & $5.6 \pm 0.8$ & $4.0 \pm 0.4$ & $6.0 \pm 0.3$ \\
\hline & $4.2 \pm 0.2$ & $22.6 \pm 1.6^{*}$ & $21.4 \pm 2.8^{*}$ & $26.2 \pm 2.7 * *$ & $26 \pm 1.9 *$ & $19.4 \pm 2.0 *$ & $20.4 \pm 1.8^{*}$ & $21.6 \pm 2.6^{*}$ & $21.2 \pm 3.5^{*}$ & $22.0 \pm 3.7 *$ & $22.0 \pm 4.0 *$ \\
\hline \multirow[t]{2}{*}{ Caffeine (only) } & $4.2 \pm 0.2$ & $16.2 \pm 4.8^{*}$ & $26.6 \pm 2.6 * *$ & $22.2 \pm 6.3^{*}$ & $24.8 \pm 5.5 * *$ & $29.8 \pm 2.6^{* *}$ & $21.8 \pm 7.3 *$ & $23.4 \pm 7.6^{*}$ & $16.6 \pm 4.7 *$ & $17.2 \pm 6.2 * *$ & $13.2 \pm 4.8$ \\
\hline & $4.2 \pm 0.2$ & $19.4 \pm 2.5$ & $28.4 \pm 2.3 *$ & $23.2 \pm 2.0$ & $33.4 \pm 2.2 * *$ & $30.8 \pm 3.1$ & $35.6 \pm 3.0 * *$ & $33.6 \pm 2.1$ & $23.2 \pm 0.7$ & $28.8 \pm 2.1$ & $29.8 \pm 2.0$ \\
\hline \multirow[t]{2}{*}{ Caffeine +Prazosin } & $4.3 \pm 1.9$ & $9.2 \pm 1.7$ & $14.2 \pm 3.3$ & $22.4 \pm 2.1^{*}$ & $22.2 \pm 3.5$ & $16.2 \pm 3.9$ & $14.8 \pm 3.5$ & $16.4 \pm 3.6$ & $12.8 \pm 2.1$ & $15.6 \pm 1.6$ & $11.2 \pm 2.3$ \\
\hline & $4.6 \pm 0.6$ & $15.2 \pm 2.7 *$ & $18.8 \pm 4.9 *$ & $24.2 \pm 4.2 * *$ & $27.8 \pm 2.4 * *$ & $22.2 \pm 2.1 * *$ & $24.4 \pm 3.3 * *$ & $16.4 \pm 3.6^{*}$ & $16.2 \pm 4.5$ & $15.6 \pm 3.3$ & $16.2 \pm 3.1$ \\
\hline Caffeine +Propranolol Rest & $4.3 \pm 2.0$ & $8.4 \pm 1.8$ & $11.4 \pm 1.6$ & $9.8 \pm 0.8$ & $7.6 \pm 2.3$ & $8.4 \pm 1.9$ & $8.2 \pm 1.4$ & $6.8 \pm 1.4$ & $5.4 \pm 0.7$ & $9.2 \pm 0.8$ & $9.1 \pm 0.7$ \\
\hline Contraction & $4.8 \pm 1.1$ & $13.6 \pm 4.3$ & $22.6 \pm 5.5 * *$ & $23.8 \pm 4.4 * *$ & $22.8 \pm 3.6 * *$ & $23.2 \pm 3.4 * *$ & $20.2 \pm 3.1 * * *$ & $16.4 \pm 2.6^{* * * *}$ & $18.8 \pm 2.5 * *$ & $14.4 \pm 3.2 * *$ & $13.1 \pm 3.6$ \\
\hline \multicolumn{12}{|l|}{ Caffeine + Prazosin Rest } \\
\hline + Propranolol & $4.3 \pm 2.0$ & $7.4 \pm 1.8$ & $10.4 \pm 1.6$ & $8.8 \pm 0.8$ & $7.2 \pm 2.3$ & $7.4 \pm 1.9$ & $7.2 \pm 1.4$ & $6.1 \pm 1.4$ & $5.6 \pm 0.7$ & $6.2 \pm 0.8$ & $6.2 \pm 0.7$ \\
\hline Contraction & $6.6 \pm 0.6$ & $16.8 \pm 1.5^{* *}$ & $14.4 \pm 3.7$ & $16.2 \pm 2.8 *$ & $16.2 \pm 5.5$ & $18.4 \pm 2.6 * *$ & $23 \pm 4.3 *$ & $19.8 \pm 3.2 * *$ & $15.4 \pm 4.3$ & $19.2 \pm 5.0$ & $21.4 \pm 3.7 *$ \\
\hline
\end{tabular}


Adrenergic receptors and caffeine on canine hindlimb glucose uptake

Perhaps, the most significant result in this study on the mechanism of increased hindlimb glucose uptake in response to caffeine is the involvement of alpha and beta adrenergic receptors under resting conditions and not during hindlimb contraction.

In conclusion, the present study showed that alpha and beta adrenergic receptors are involved in caffeine- induced-hyperglycemia at rest and during hindlimb contraction. It also showed that while both alpha and beta adrenergic receptors are involved in caffeine induced increases in glucose extraction and hindlimb glucose uptake at rest, these receptors are not involved in caffeine-induced increases in glucose extraction and hindlimb glucose uptake during hindlimb contraction.

\section{References}

Ajala, M. O., Oladipo, O. O, Fasanmade, O. and Adewole, T. A. (2003). Laboratory assessment of three glucometers. Afr. J. Med. med. Sci. 32: 279-282.

Akiba, T., Yaguchi, K., Tsutsumi, K., Nishioka, T., Koyama, I., Nomura, M., Yokogawa, K., Moritani, S. and Miyamoto, K. (2004). Inhibitory mechanism of caffeine on insulinstimulated glucose uptake in adipose cells. Biochem Pharm. 68: 1929-1937.

Alada, A. R. A. and Oyebola D. O .O. (1997). The role of adrenergic receptors in the increased glucose uptake by canine gut. Afr. J. Med. med. Sci. 26: 75-78.

Al-Jibouri, L. M., Furman, B. L. and Parrant, J. R. (1980). Blockade of adrenaline-induced hyperglycemia in anaesthetized cat by continuous infusion of phentolamine and propranolol. Br. J. Pharmacol. 68: 461-466.

Antonis, A., Clark, M. L. and Hodge, R. L. (1967). Receptor mechanisms in the hyperglycemic response to adrenaline in man. Lancet. 11351137.

Canto, C., Chibalin, A. V., Barnes, B. R., Glund, S., Suarez, E., Ryder, J. W., Palacin, M., Zierath, J. R., Zorrano, A. and Gauma, A. (2006). Neuregulin mediate calcium-induced glucose transporter during muscle contraction. J. Biol. Chem. 281: 21690-21697.

Chukwu, L. O., Odiete, W. O. and Briggs, L. S. (2006). Basal metabolic regulatory responses and rhythmic activity of mammalian heart to aqueous kolanut extracts. Afr. J. Biotech. 5: 484-486.

Costill, D. L., Dalsky, G. P., Fink, W. J. and LeBlanc, J. (1978). Effects of caffeine ingestion on metabolism and exercise performance. Med. Sci. Sports Exerc. 10:155-158.

Deibert, D. C. and De Fronzo, R. A. (1980). Epinephrine - induced insulin resistance in man J Clin Invest. 65: 717 - 721.

Devreese, K. and Leroux-Roels, G. (1993). Laboratory assessment of five glucose meters designed for self monitoring of blood glucose concentration. Eur. J. Clin. Biochem. 12:829837.

Fredholm, B. B. (1998). Adenosine, adenosine receptors and the actions of caffeine. Pharmocol. Toxicol 76: 93-101.

Fredholm, B. B., Battig, K., Holmen, J., Nehlig, A., and Zvartau, E. E. (1999). Actions of caffeine in the brain with special reference to factors that contribute to its widespread use. Physiol. Rev. 51: 83-133.

Graham, T. E., Sathasivam, P., Rowland, M., Marko, N., Greer, F. and Battram, D. (2001). Caffeine ingestion elevates plasma insulin response in humans during an oral glucose tolerance test. Can. J. Physiol. Pharm. 79: 559565.

Graham, T. E. and Spriet, L. L. (1995). Metabolic, catecholamine, and exercise performance responses to various doses of caffeine. J. Appl. Physiol. 78:867-874.

Graham, T. E., Helge, J. W., and Maclean, D. A. (2000). Caffeine ingestion does not alter carbohydrate or fat metabolism in human skeletal muscle during exercise. J. Physiol. (Lond). 529: 837-847.

Greer, F., Hudson, R., Ross, R. and Graham, T. E. (2001). Caffeine decreases glucose disposal during an englycemic hyperinsulinemic clamp in sedentary males. Diabetes. 50: 2349 - 2354.

Hamada, T., Hayashi, T., Kimura T., Nakao K, and Moritani T. (2004). Electrical stimulation of human lower extremities enhances energy consumption, carbohydrate oxidation, and whole body glucose uptake. J. Appl. Physiol. 96: 911-916.

Han, D. H., Hansen, P. A., Nolte, L. A. and Holloszy, J. O. (1998). Removal of adenosine decreases the responsiveness of muscle decrease transport to insulin and contractions. Diabetes. 47: 1671 - 1675.

Hardie, D. G. and Sakamoto, K. (2006). AMPK: A key sensor of fuel and energy status in skeletal muscle. Physiol. 21: 48-60.

Jensen, T. E., Rose, A. J., Hellsten, Y., Wojtaszewski, J. K. and Richter, E. A. (2007). Caffeine-induced $\mathrm{Ca}++$ release increases AMPK-dependent glucose uptake in rodent soleus muscle. Am. J. Physiol 293: E286-E292.

Keijzers, G. B., De Galan, B. E., Jack, G. and Smits, P. (2002). Caffeine can decrease insulin sensitivity in humans. Diabetes Care. 25: 364 369.

Lee, S., Hudson, R., Kilpatrick, K., Graham, T. E. and Ross, R. (2005). Caffeine ingestion is associated with reductions in glucose uptake independent of obesity and type 2 diabetes before and after exercise training. Diabetes Care. 28: 566-572. 
H. M. SALAHDEEN and A. R. A. ALADA

Ogutuga, D. B. A. (1975). Chemical composition and potential commercial uses of kolanuts, Cola nitida vent Cachott and Endlisher. Gh. J. Agri. Sci. 8: 121-125.

Oyebola, D. D. O. and Durosaiye, G. O. (1988). Effect of adrenaline and propranolol on glucose uptake in the canine terminal ileum. Niger. J. Physiol. Sci. 4: 31-37.

Oyebola, D. D. O. and Alada, A. R. A. (1993). Effects of adrenergic receptors blockers on adrenerline and nicotine-induced hyperglycemia in the rat. Afri. J. Med med Sci. 22: 13-18.

Pencek, R. R., Battram, D., Shearer, J., James, F. D., Lacy, D. B., Jabbour, K., Williams, P. E., Graham, T. E. and Wasserman, D. H. (2004). Portal vein caffeine infusion enhances net hepatic glucose uptake during a glucose load in conscious dogs. J. Nutr. 134: 3042-3046.
Petrie, H. J., Chown, S. E., Belfie, L. M., Duncan, A. M., McLaren, D. H., Conquer, J. A. and Graham, T. E. (2004). Caffeine ingestion increases the insulin response to an oralglucose-tolerance test in obese men before and after weight loss. Am. J. Clin. Nutri. 80: 22-28.

Richter E.A. (1996). Glucose utilization. In: Handbook of Physiology. Exercise: Regulation and Integration of Multiple Systems. Bethesda, MD. Sect. 12, p. 913-951.

Robinson, L. E., Savani, S., Battram, D. S., McLaren, D. H., Sathasivam, P. and Graham, T. E. (2004). Caffeine ingestion before an oral glucose tolerance test impairs blood glucose management in men with type 2 diabetes. $J$. Nutr. 134: 2528-2533.

Received: October 5, 2009

Accepted: December 18, 2009 